\title{
Effect Short-term Aquarobics Exercise on Cholesterol Levels
}

\author{
Siti Baitul Mukarromah ${ }^{1}$, Sugiarto $^{2},{\text { Mohammad Arif } \mathrm{Ali}^{3} \text {, Gustiana Mega Anggita }}^{4}$, Anies \\ Setiowati ${ }^{5}$, Ronny Lesmana ${ }^{6}$ \\ \{ sitibaitul@mail.unnes.ac.id ${ }^{1}$, sugiarto@mail.unnes.ac.id², hiarifalikhan@mail.unnes.ac.id ${ }^{3}$ \} \\ Faculty of Sports Science, Universitas Negeri Semarang, Semarang, Indonesia ${ }^{1,2,3}$
}

\begin{abstract}
The purpose of this study was to determine the effect of the duration of aquarobics exercise on blood lipid profiles in 30 male students of the Sport Science (Sports, Health) Study Program, FIK UNNES, aged 21-22 years. The experimental laboratory research design using the design of The Randomized Pretest-Posttest Control Group Design, measurement of the blood lipid profile which includes of TC, TG, HDL and LDL blood levels. Measuring cholesterol levels is carried out using the automatic analyzer method (electronic resistance / impedance \& volumetric metering), at the Prodia Semarang Laboratory. After pre-test the sample was divided into 3 groups where each group consisted of 10 students, group $1(n=10)$ aquarobics training intensity $70-85 \%$ HRmax for 8 weeks, group $2(n=10)$ resistance training with $75 \%$ RPM for 8 weeks and control group $3(n=10)$. The result showed that the Aquarobics training has better effect in HDL and Triglyceride levels.
\end{abstract}

Keywords: intensity, aquarobics, cholesterol

\section{Introduction}

Basic methods and techniques in the study of sports science play an important role in efforts to establish and improve individual health status. Physical conditioning exercises that are carried out regularly with the right dose can benefit health, fitness, performance and management programs for functions in the body. Aerobic exercise, including aquarobics, can be an option and it is also a modulator in the non-pharmacological management of the cardiovascular system. The negative impact caused by changes in life patterns that are all practically and instantaneous, especially in big cities is an increase in the prevalence rate of Atherosclerotic Cardiovascular Disease (PKVAS) which is caused by physiological changes in the body, especially the composition of blood and life at its level, as a cause of death in Indonesia.[1] Previous studies show a strong correlation between blood cholesterol levels and PKVAS morbidity, as well as between LDL cholesterol levels in the blood and artherosclerosis, while on the other hand there is a significant negative correlation between HDL cholesterol and Coronary Heart Disease.[2] Previous studies have found that high levels of LDL cholesterol in the blood can be used as a predictor of the risk of developing PKVAS, while HDL cholesterol is a protective element against the risk of PKVAS. Physical exercise or regular exercise with the right dose is one of the efforts to prevent PKVAS, this is supported by research results which show that physical exercise can actually improve dyslipidemia which is the cause of PKVAS.[3,4] Several scientific and physical exercise programs for 
blood cholesterol management have yielded mixed outcomes. According to certain researchers, physical exercise programs have not entirely helped in the management of dyslipidemia since certain high doses of physical activity can diminish blood vessel quality.[5,6]

There two types of exercises used in this study, namely weight training performed on land and aquarobics training performed on water. Both types of training have advantages and disadvantages, the advantage of weight training is the best training to increase muscle mass and muscle strength. Previous studies have reported that regular weight training for 8 weeks with a duration of 60 minutes, a frequency of 3-4 days can increase muscle approximately 1.4 $\mathrm{kg}$. Another study using Brisk walking 60 minutes/day, intensity moderate exercise for 8 weeks can improve immunity. Weight training provided includes flexibility training, isometric strengthening exercises, isokinetic and isotonic.[7] The disadvantage of weight training is that it can cause the risk of injury, while the excess of aquarobics training is sports training that has a minimal risk of injury. [8]Aquarobics exercises have a lower risk impact on the limbs, joints and muscles due to the nature of water. Water resistance provides the advantage that it is very good for training muscles, because of this obstacle the movement becomes lighter. This resistance serves as a load to train all parts of the body's muscles. [9,10] Previous studies have reported that exercise in waist-deep water can reduce stress on the joints by $50 \%$ and chest level reduce stress on the joints by as much as 75\%.[11]

Physical activity is the only side effect of dose-response exercise (Exercise intensity, frequency, and duration), so far, research protocols relating to exercise methods have been carried out utilizing dosage exercise, which necessitates a significant amount of effort from the individual who want to participate, which can be a barrier for some people. As a result, it is critical to establish a workout approach and approach that is inexpensive, safe, and enjoyable, requires little attention, effort, or time, and is successful in improving blood lipid profiles.

\section{Methods}

Thirty male Sport Science students, ages 19 to 22, who had not participated in gymnastics for at least three months before to the study. The participants were split into three groups at random: (1) aquarobics exercise, (2) weight training $(\mathrm{n}=10)$ and (2) resistance training week for 8 weeks $(n=10)$ and the control group $(n=10)$. Weight training with a 75 percent RM (maximum reps) intensity, 12 repetitions ( 3 sets), and a frequency of every 2 days was used in this study, as was aerobic training with an intensity of 75-85 percent HRmax (maximum heart rate), a frequency of every 2 days, and a duration of 60 minutes. The 2-day frequency was chosen based on ACSM's suggestion that a decent fitness activity should be done once every two days since muscle mass will return to baseline after $2 \times 24$ hours.

\subsection{Research procedures}

Participants were told about all procedures before receiving therapy, which were approved by the Commission of Research Ethics Dr Kariadi Hospital, Diponegoro University, Semarang (No.498/EC/FK/RSDK/2019). At the morning pre-test, respondents received their informed consent and underwent a preliminary examination. Using weight scales and a Body 
Scan Analyzer, eligible individuals' height and weight were measured in order to calculate their body mass index (BMI) (Inbody 230 Body Fatt Monitor).

\subsection{Exercise training protocol}

Resistance training $(n=10)$, aquarobics $(n=10)$, and control groups $(n=10)$ were assigned to participants at random. All subjects' anthropometric measurements were checked (Pre-test and post test). HDL and Triglyceride serum were obtained immediately before and after the exercise. Warm-up and cool-down time for each group is 10-15 minutes, with a weighttraining regimen for the upper and lower body. All of the subjects followed the schedule to the letter, with a minimum of $95 \%$ attendance at the training sessions. The participants were not experienced with aquarobics workouts at the time, and a heart rate monitor was used every 5 minutes during moderate intensity exercise (75-85 percent HRmax): Warm-up for 15 minutes, aerobic dancing and stretching for 20 minutes, aquajogging, aquarun, and aquagames for 20 minutes, and cool-down for 15 minutes (cool down).

\subsection{Pre-test and post-test}

Three groups were given a pre-test before the start of the meeting exercises. Body mass index, total cholesterol, triglyceride, LDL, and HDL values were all measured prior to the test. Measurements made with an enzymatic colorimetric spectrophotometer using the direct approach. After 8 weeks of treatment, a post-test exercise was performed.

\subsection{Statistical analysis}

The data is presented in a nominal and ordinal frequency distribution, with data intervals and ratios presented by mean and standard deviation in graphs and tables.Hypothesis testing was carried out by testing the normality of the data with the Shapiro-Wilk test and the test of homogeneity with homogenity of variance Levene statistics against data. Normal distribution of data $(\mathrm{p}>0.05)$ and variants of homogeneous data analyzed by parametric one-way ANOVA followed by Tukey HSD post hoc test (honestly significant difference). Data that was not normally distributed $(\mathrm{p}<0.05)$ or had non-homogeneous variance was analyzed using non-parametric analysis using the Kruskal-Wallis test and was followed by the Mann-Whitney difference test. All statistical analyses were performed using SPSS-PC for Windows (version 20.0, SPSS Inc., Chicago, IL, USA).

\section{Result and Discussion}

The data that was successfully summarized through the research data collection procedure consisted of data on age, weight, height which had the same relative value (homogeneous) for each sample. Total cholesterol, triglycerides, LDL cholesterol, and HDL cholesterol levels are all blood lipid variables. Table 1 provides a general overview of the subject's characteristics. 
Table 1. Comparison of characteristics subject

\begin{tabular}{lllll}
\hline Variable & $\begin{array}{l}\text { Aquarobic } \\
\text { mean } \pm \text { SD }\end{array}$ & $\begin{array}{l}\text { Resistance training } \\
\text { mean } \pm \text { SD }\end{array}$ & $\begin{array}{l}\text { Control group } \\
\text { mean } \pm \text { SD }\end{array}$ & $\mathrm{p}$ \\
\hline Age (years) & $21.74 \pm 1.30$ & $21.49 \pm 1.41$ & $21.79 \pm 1.35$ & 0.225 \\
Intake energy (kcal) & $3125 \pm 165.81$ & $3157 \pm 119.97$ & $3134 \pm 136.11$ & 0.112 \\
Intake protein (g) & $54.78 \pm 1.67$ & $58.49 \pm 1.67$ & $55.38 \pm 1.78$ & 0.608 \\
Intake fat $(\mathrm{g})$ & $73.93 \pm 3.12$ & $69.87 \pm 3.83$ & $65.66 \pm 3.34$ & 0.265 \\
Height $(\mathrm{m})$ & $1.75+0.05$ & $1.72+0.04$ & $1.72+0.04$ & 0.151 \\
Weight $(\mathrm{kg})$ & $73.66 \pm 5.54$ & $75.41 \pm 3.11$ & $73.41 \pm 6.61$ & 0.539 \\
Body fat pre (\%BF) & $35.82 \pm 1.00$ & $36.64 \pm 1.58$ & $37.48 \pm 1.05$ & 0.074 \\
Body fat post $(\% \mathrm{BF})$ & $31.44 \pm 1.26$ & $32.61 \pm 1.11$ & $35.03 \pm 1.16$ & $0.000^{*}$ \\
BMI (kg/m) pre & $30.32 \pm 0.97$ & $30.73 \pm 1.13$ & $30.84 \pm 1.30$ & 0.195 \\
BMI (kg/m) post & $29.24 \pm 1.18$ & $31.70 \pm 0.92$ & $30.66 \pm 1.69$ & $0.000^{*}$ \\
\hline
\end{tabular}

Information: data are expressed as mean and $\mathrm{SD}$, significant difference between groups $(\mathrm{p}<0.05)$

The average age of the study subjects, height, and weight before and after treatment were not statistically significant in any of the groups, but the percentage of body fat and BMI after treatment in the treatment group were significantly different (p0.05) from the control group. We used a 24-hour food recall to measure food intake in this investigation, based on the results of the Nutris computation. In this study, where food intake was measured using a 24 hour meal recall, the level of calorie, protein, and fat consumption in each group was not substantially different $(p=0.112 ; p=0.608 ; p=0)$, according to the results of the Nutrisoft software calculations.

These findings demonstrate that food intake throughout treatment was the same in all groups, indicating that food intake had no bearing on the study's findings. After the ShapiroWilk test revealed that the distribution of BMI data before and after in the treatment and control groups had $\mathrm{p}>0.05$, one-way anova parametric analysis was performed, and the difference test was performed using the Tukey HSD parametric test. The data distribution is not normal, so the data analysis used was the Kruskal-Wallis non-parametric test, followed by the Mann Whitney test. The BMI delta test has a p0.05 in the Shapiro-Wilk test, the data distribution is not normal, so the data analysis used was the Kruskal-Wallis non-parametric test, followed by the Mann Whitney test. When compared to the control group, BMI changes considerably in the aquarobics and weight training groups (p0.05).

Table 2. Comparison pre and post intervention

\begin{tabular}{lllll}
\hline Variable & $\begin{array}{l}\text { Aquarobic } \\
\text { mean } \pm \text { SD }\end{array}$ & $\begin{array}{l}\text { Resistance training } \\
\text { mean } \pm \text { SD }\end{array}$ & $\begin{array}{l}\text { Control group } \\
\text { mean } \pm \text { SD }\end{array}$ & $\mathrm{p}$ \\
\hline Total Cholesterol (mg/dl) pre & $216.33 \pm 40.95$ & $238.33 \pm 49.86$ & $192.25 \pm 37.42$ & 0.144 \\
Total Cholesterol (mg/dl) post & $190.75 \pm 35.43$ & $199.83 \pm 25.63$ & $164.00 \pm 17.80$ & $0.003^{*}$ \\
LDL-C (mg/dl) pre & $137.75 \pm 17.82$ & $158.58 \pm 25.90$ & $134.00 \pm 6.12$ & 0.124 \\
LDL-C (mg/dl) post & $123.92 \pm 14.38$ & $144.92 \pm 19.16$ & $128.58 \pm 5.76$ & $0.002^{*}$ \\
HDL-C (mg/dl) pre & $5717 \pm 5.50$ & $54.33 \pm 5.29$ & $50.50 \pm 4.75$ & 0.079 \\
HDL-C (mg/dl) post & $61.83 \pm 4.85$ & $64.17 \pm 5.06$ & $57.00 \pm 4.55$ & $0.003^{*}$ \\
Triglyceride (mg/dl) pre & $119.17 \pm 35.14$ & $131.50 \pm 37.01$ & $112.75 \pm 9.42$ & 0.160 \\
Triglyceride (mg/dl) pre & $99.33 \pm 29.95$ & $105.25 \pm 23.87$ & $73.92 \pm 10.11$ & $0.004^{*}$ \\
\hline
\end{tabular}

Information: Significant difference between groups (p0.05) is presented as mean and SD. 
Total cholesterol (TC) and LDL cholesterol (LDL-C) levels were not statistically significant before and after treatment in all groups, but HDL cholesterol (HDL-C) and triglycerides (TG) levels after treatment were significantly different (P 0.05) in the treatment group compared to the control group. Aquarobics exercises given by heating for 5-10 minutes followed by the fundamental exercise of measuring the pulse submaximal $75-85 \%$ HRmax is 200 minus age who are training per minute, training is given 45-60 minutes and then terminated by cooling for 5-10 minute. Aquarobics exercise provided more than 30 minutes to reach the breakdown of fat, the energy generated from the metabolism of fats doubled compared to the energy produced by carbohydrates. Aquarobics exercise uses fat as fuel, especially if the load is light to moderate. If done regularly and continuously not only all physical fitness increased but bad blood lipid levels (LDL cholesterol, total cholesterol, triglycerides) decreased, whereas levels of good fats (HDL cholesterol) will increase. [12]

Decreased levels of triglycerides in this study occurred due to several factors, including, increased exercise activity, increase cardiac work done as a result of weight training and an increase in lipolysis process in energy expenditure during exercise. Triglycerides have a variety of functions in the human body is one of them as a source of energy that has a role similar to the carbohydrates. Another function is no less important than triglycerides for the human body is as an energy reserve that can be used when the body needs energy right away.[13] Excess fatty foods consumed will be stored as body fat, stored in fat tissue, called adipocytes, while the shape of the body is adipose fat tissue. Cell body releases triglycerides and fatty acids, and sent through the bloodstream to the cells that need energy.[14]

A decrease in plasma triglycerides can be triggered by acute exercise in the short term, a previous study found a decrease in plasma triglycerides occurs between 12-18 hours after exercise and last 2-3 days. The decrease in triglycerides is caused by a decrease in the concentration of triglycerides in the form of VLDL which they need as energy during exercise. Exercise maintain a long-term reduction in plasma triglycerides in sedentary, exercise should be done regularly at least every third day in order to stay awake triglyceride levels. The increase in HDL blood levels caused by aquarobics training is attributed to an increase in LPL activity, which leads to an increase in triglyceride-rich lipoprotein catabolism, speeding up the removal of surface components from HDL lipoproteins.[15]

Increased HDL levels due to aerobic exercise because fat is used as an energy source, resulting in lower triglyceride and VLDL levels, which finally led to higher HDL levels. [16] Several suggestions on the mechanism of increased HDL levels as a result of physical activity have been reported in other studies: 1) Physical activity raises the level of the enzyme LPL in muscle tissue. 2) Physical exercise can reduce HepaticTriglyseride-Hydrolase enzyme activity in the liver and block HDL catabolism, resulting in enhanced VLDL catabolism and higher HDL levels in plasma. [17] The dose response exercise reveals that an activity volume with a calorie burn of $1200-2200 \mathrm{kcal} /$ week is an effective workout that increased of HDL-C (2-8 $\mathrm{mmol} / \mathrm{L})$ levels.[18,19]

Based on the findings of determining the minimum duration aquarobics exercise management of blood cholesterol levels of Total Cholesterol (TC), triglycerides (TG), LDL cholesterol (LDL-C), and HDL cholesterol (HDL-C), it can be concluded that aquarobics exercise at an intensity of 75-85 percent HRmax has an effect on decreasing triglyceride levels and increasing blood HDL levels in male students. 


\section{Conclusion}

Increased adiponectin and appearance characterized by lower triglyceride (TG), increased HDL Cholesterol (HDL-C, aquarobics exercise can be utilized as an effective nonpharmacological treatment.

\section{References}

[1] Cokroprawiro, 1997 Cokroprawiro A, 1997. Gulohcirsar: 'Syndrome-10' ten guidelines healty life prevention of atero-sclerosis. (Simposium chalange in the management of hypercholesterolemia). Surabaya, 9 maret.

[2] Mc Gilvery dan Robert, 1983 Mc Gilvery Robert, 1983. Biochemistry a function aproach. WB Sounders Company).

[3] Angelopoulus, 1993; Angelopoulos TJ, et.al, 1993. Effect of repeated exercise bouts on high density lipoprotein cholesterol and its subfraction HDL-2 C and HDL-3 C. Int J Sport Medicine, 14. 1996: 201.

[4] Jeyaamalar, 1994, Jeyaamalar R, 1994. Hyperlipidemia: Importance and management. Med Digest. $12(3): 1-13$.

[5] Friedenreich CM, Woollcott CG, McTiernan A, et al. Adiposity changes after a 1-year aerobic exercise intervention among postmenopausal women: a randomized controlled trial. Int $\mathbf{J}$ Obes (Lond). 2010.)

[6] F. J. Penedo and J. R. Dahn, "Exercise and well-being: a review of mental and physical health benefits associated with physical activity," Current Opinion in Psychiatry, vol. 18, no. 2, pp. 189193, 2005.

[7] McTiernan A, Sorensen B, Irwin ML, et al. Exercise effect on weight and body fat in men and women. Obesity (Silver Spring). 2007; 15:1496-512.)

[8] A. Cider, M. Schaufelberger, K. S. Sunnerhagen, and B. Andersson, "Hydrotherapy-a new approach to improve function in the older patient with chronic heart failure," European Journal of Heart Failure, vol. 5, no. 4, pp. 527-535, 2003)

[9] A. Foley, J. Halbert, T. Hewitt, and M. Crotty, "Does hydrotherapy improve strength and physical function in patients with osteoarthritis - a randomized controlled trial comparing a gym based and a hydrotherapy based strengthening programmed," Annals of the Rheumatic Diseases, vol. 62, no. 12 , pp. 1162-1167, 2003.

[10] T. P. Reilly, C. N. Dowzer, and N. T. Cable, "The physiology of deep-water running," Journal of Sports Sciences, vol. 21, no. 12, pp. 959-972, 2003.

[11] E. Gappmaier, W. Lake, A. G. Nelson, and A. G. Fisher, "Aerobic exercise in water versus walking on land: effects on indices of fat reduction and weight loss of obese women," Journal of Sports Medicine and Physical Fitness, vol. 46, no. 4, pp. 564-569, 2006.

[12] Dede Kusmana, 2006, Dede Kusmana, 2006, Olahraga Untuk Orang Sehat Dan Penderita Penyakit Jantung, Jakarta: Balai Penerbit FKUI.

[13] Sherwood L. Fisiologi Manusia Dari Sel ke Sistem. Edisi ke-6. Jakarta: ECG; 2011. p. 642-3

[14] Guyton A.C, Hall J.E. Buku Ajar Fisiologi Kedokteran. Edisi ke-11. Jakarta: ECG; 2006. p. 884-5

[15] Nielson EP, 1986, Nielson EP, 1986, Lipolitic Enzymes and Plasma Lipoprotein Metabolisme, Garfinkel AS: Scholt MC. Ann Rev Biochem.

[16] Leaf DA, 1991 Leaf DA, 1991, Exercise and Nutrition in Preventif Cardiol-ogy, Los Angeles: Brown and Bencmark.

[17] Juanita D, 1991 Juanita D, 1991, Pengaruh Latihan Aerobik Dan Anaerobik Terhadap Proofil Lipid Pada Tikus Rattus Norwegiua Wistar, Surabaya: Tesis UNAIR.

[18] Ring Dimitrrou, 2007, Ring Dimitrrou Sussane, 2007, Nine Months Aerobic Fitness Induced Changes on Blood Lipids and Lipoproteins In Untried Subjects Verus Control, European Journal Of Applied Physiology. 
[19] T. Bahri Anwar Djohan, 2004, Penyakit Jantung Koroner Dan Hypertensi, Sumatera: USU Repository. 